\title{
FILOSOFÍA DE LA REDENCIÓN
}

\author{
RESEÑA DEL LIBRO: PHILIPP MAINLÄNDER. FILOSOFÍA DE LA REDENCIÓN. \\ TRADUCCIÓN DE SANDRA BAQUEDANO JER. SANTIAGO: FONDO DE CULTURA \\ ECONÓMICA, 2021 (516 PP.).
}

\author{
Ignacio Moya \\ (Western University) \\ ignaciomoyaa@gmail.com
}

Recibido: $31 / 12 / 2021$

Aprobado: 30/01/2022

\section{La filosofía de la redención}

\section{Philipp Mainländer}

Edición, traducción y estudio preliminar Sandra Baquedano Jer

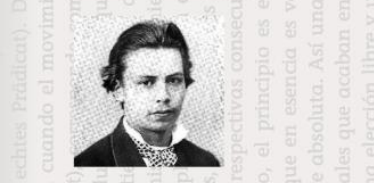

倩

alemán Philipp Batz - más conocido por su seudónimo Philipp Mainländer. Y lo cierto es que no pudo haber un mejor momento. La profesora Baquedano ya nos presentó anteriormente una excelente antología de La filosofía de la redención (Fondo de cultura económica, 2011, 141 pp) y en esta oportunidad nos regala la traducción completa de este libro. Esto representa, sin duda, un aporte valioso para toda la filosofía de habla hispana. En especial porque la obra de Mainländer, y el pesimismo filosófico en general, está adquiriendo un renovado interés en todo el mundo y Baquedano pone a disposición de todos los hispanohablantes una obra que es central para conocer el pesimismo filosófico.

Mainländer es el filósofo más trágico en la tradición pesimista - tradición que incluye a Schopenhauer, von Hartmann y Julius Bahnsen. Es el más trágico porque, por un lado, su filosofía es una que nos llama a enfrentar nuestro destino de manera directa - siendo ese destino la muerte. Por otro lado, tal como Baquedano nos relata en la sección Estudio preliminar, Mainländer se suicidó horas después de haber recibido la primera edición de su Filosofía de la redención. Con este acto, Mainländer logró dos cosas tremendamente importantes. Uno, hizo realidad el argumento central de su obra: que nuestro destino es la muerte, que fuimos creados para morir. Dos, que el suicidio, más que un problema filosófico, una debilidad de caracter o un trastorno psicológico, es un acto de redención. 
Baquedano nos recuerda que el suicidio ha sido una preocupación filosófica al menos desde que Sócrates decidiera ponerle termino a su propia vida. Muy apropiadamente, entonces, en su Estudio preliminar, Baquedano incluye una sección llamada Estudiar el suicidio por causa ontológica. Esta sección es muy importante y un gran acierto puesto que aborda, a mi juicio, al tema central en la filosofía de Mainländer: el suicidio. Lo cierto es que sería erróneo sostener que la filosofía Mainländeriana es una apología al suicidio - este punto lo deja claro Baquedano cuando dice que $<<$ La filosofía de la redención no exhorta en general al suicidio [más bien] despeja y destruye contramotivos de enorme poder que condenan el acto y a quienes lo cometieron.> $>$ Entonces aunque no es correcto leer la obra de Mainländer como una defensa del suicidio, sí es esencial reconocer que el suicidio ocupa un lugar central e ineludible. El suicidio está siempre presente, siempre en el fondo y, a ratos, en primera línea.

En este sentido, es pertinente recordar que la primera línea en el libro El mito de Sísifo, Camus nos dice que la pregunta filosófica más urgente es la pregunta por el suicidio. Después de todo, si la vida no vale la pena vivirla, entonces todas las otras preguntas filosóficas -qué es la ética, cuál es la mejor forma de organización política- pasan a ser irrelevantes. En última instancia, Camus termina diciendo que, en medio de esta absurda existencia, nuestras vidas pueden encontrar propósito y que vale la pena seguir existiendo. Pero la respuesta de Camus tiene sentido únicamente en la medida en que aceptemos que la existencia no tiene propósito y que en consecuencia nosotros podemos darnos un propósito. Aquí es donde radica, quizás, uno de los aportes más importantes de Mainländer. Él dice que el universo sí tiene un propósito y razón de ser. Que sí fue creado con un fin en mente. Sin embargo, más que darnos tranquilidad, en la metafísica Mainländeriana la afirmación de que el universo tiene una razón de ser puede llegar a ser una fuente de ansiedad y angustia. Esto porque si existimos, no es porque tengamos algo hacer con nuestras vidas, no es porque tenemos un objetivo que puede guiar y darles propósito a nuestras existencias. $\mathrm{O}$ al menos eso parece, pues es aquí donde la genialidad de Mainländer parece jugarnos una mala pasada.

Tomando como punto de partido el postulado existencialista de que estamos colgando sobre el vacío y la nada de la existencia, muchos han buscado llenar esa nada con algo porque pensamos que un algo (lo que sea) es siempre mejor que una nada. Pues Mainländer nos ha dado ese algo, pero en su caso ese algo es la muerte, la nada absoluta. Mientras que Schopenhauer dijo que somos voluntad-de-vivir, Mainländer dijo que somos voluntad-para-morir. Esto significa que vivimos sólo para desgastar energía, para morir y alcanzar la nada absoluta. Nacemos para desaparecer. El algo que nos ha dado Mainländer es un algo que en realidad es una nada.

El universo que nos presenta Mainländer avanza raudo hacia la nada absoluta. Esto se explica porque en su metafísica hubo un momento en que Dios existía en completa soledad. Era una unidad simple y absoluta, omnipotente sobre todo, menos sobre su existencia. Esto significa que Dios se vio a sí mismo y comprendió el tedio de una existencia que consistía en sólo ser, en sólo estar, y en nada más. Ante ese tipo de existencia, Dios tomó la decisión de poner término a su vida. Sin embargo, dado que no poseía el poder para terminar con su propia existencia directamente (pues carecía de poder sobre su propia esencia), decide hacer lo único que podía hacer: desintegrarse en múltiples fragmentos, quebrando así la unidad primaria. De esta manera, cada individuo, cada fragmento, cada existente estaba en condiciones de entrar en contacto con otros existentes y agotar su voluntad, su energía vital hasta morir y dejar de ser. En algún momento, entonces, la energía total del universo desaparecerá y sólo quedará una nada absoluta. Y cuando esto ocurra, Dios habrá logrado su cometido y cada uno de nosotros habrá cumplido su parte y habrá llevado a cabo el último deseo de Dios -morir y dejar de ser.

Baquedano, de forma muy acertada, hace un interesante paralelo entre la metafísica de Mainländer y los recientes avances en física y las distintas teorías acerca del origen del universo -específicamente la teoría del big bang. Las semejanzas son importantes y tienen que ver con la idea de una unidad simple originaria que se desintegra y da origen a todo lo que es. Para Mainländer la unidad primaria se desintegró para crear el universo con el objetivo de llevarlo a la nada. Para la física esa unidad primaria se expandió dando así también origen al universo. A este paralelo tan revelador, le podemos sumar la posibilidad física de una muerte termodinámica para el universo -un estado de equilibrio termodinámico donde el 
intercambio de energía ya no sería posible lo que implicaría la desaparición absoluta de toda energía y toda materia. Esto sería, desde el punto de vista físico, el fin del universo. Y este fin se parece mucho a la muerte que Mainländer ya adelantó en su Filosofía de la redención.

Para terminar, y si las razones ya presentadas no son suficientes para motivar al lector, es importante decir que Baquedano tiene el enorme talento de escribir muy bien. Es clara, precisa y nos ofrece una lectura amena y cercana. En ese sentido, su Estudio preliminar es fundamental pues allí ella nos entrega todo el contexto, la historia y la información necesaria para conocer y entender la extensa filosofía de Mainländer. Y en estos tiempos esto es una excelente noticia. 